\title{
PICC Line for Home Parenteral Nutrition Patients
}

\section{Caballero MCC ${ }^{*}$, Carretero JIB, Perez MAC and Sanz MM}

President of the Spanish Society of Nursing Intravenous Therapy Equipment (ETI), Hospital Pediatric Nurse, Ramon y Cajal (Madrid), Spain

${ }^{*}$ Corresponding author: Caballero MCC, President of the Spanish Society of Nursing Intravenous Therapy Equipment (ETI), Hospital Pediatric Nurse, Ramon y Cajal (Madrid), Spain, Tel: 0034620083451; E-mail: mccarrero@cateterpicc.com

Rec date: Jun 13, 2015, Acc date: Jan 21, 2016, Pub date: Jan 29, 2016

Copyright: (c) 2016 Caballero MCC, et al. This is an open-access article distributed under the terms of the Creative Commons Attribution License, which permits unrestricted use, distribution, and reproduction in any medium, provided the original author and source are credited.

\section{Introduction}

Parenteral nutrition-dependent chronic patients are those who, from the beginning of their treatment, require special strategies in terms of administering nutrition, nutritional needs, and venous access availability. Clinical and scientific evidence points to the need for proactive assessment in order to avoid serious venous access damage in their vascular anatomy.

Over the last twelve year's experience at our facility, we noted that the use of less invasive systems, such as PICCs, resulted into excellent outcomes, as long as care and maintenance protocols were properly applied.

Patients with home parenteral nutrition (HPN) have the best casuistry as they are responsible and follow PICC care protocols in the correct way, fitting maximally to technical recommendations explained by the nursery. Over the last 12 years, we've had 32 homecare patients, of whom 22 had temporal HPN and 10 chronic HPN. This homecare patients in most cases resorted to the use of the PICC line due to vascular exhaustion.

\section{Clinical Case}

\section{Background}

A patient affected by short bowel Crohn's disease who was referred to the department of Pediatrics at the age of ten, was on HPN for the last five years and carrying a port. He needed several antibiotic courses for catheter related blood stream infection (CRBSI), and requested a PICC insertion. He had a history of 32 central venous catheters (CVC) insertions that, after several CRBSI, ruined his venous access. He has been carrying different subclavian, jugular and femoral CVC as well as seven Hickman and four ports.

After antibiotic treatment, he began using the PICC line for HPN infusion. For the following 12 months we checked no new CRBSI episodes. After one year without using the port it was removed.

The patient needed a total of 4 PICCs for the following 8 years. Two of them were changed because of displacement of the insertion site; as he was a very active child who led a normal life at home. Another one was withdrawn for a suspected infection (not confirmed after culturing the tip) and the last one was changed for a Hickman catheter as recommended for intestinal transplantation which was performed in a different facility.

The PICC-carrying period was from 1996 to June 2004. He then moved to La Paz Hospital for intestinal transplantation.

In 2006 the patient dies eight months after transplantation and free of parenteral nutrition. At the request of the patient the Hickman catheter, unused for several months, was planned to be removed. The night before catheter withdrawal he suffered a CRBSI and dies $18 \mathrm{~h}$ after. 